\title{
The Limits of Leadership
}

Iwona Sobis ${ }^{1}$, Frits van den Berg ${ }^{2}$, Michiel S. de Vries ${ }^{3}$

(Paper for The $19^{\text {th }}$ NISPAcee Annual Conference "Public Administration of the Future”, 19-22 May 2011, Varna, Bulgaria.Working group on PA Reform.)

\begin{abstract}
In Public Administration, it is taken for granted that reforms are initiated and conducted by leaders. However, one can wonder whether change is indeed always coming from leadership and whether the concept thereof as the driving force behind change and the panacea for all the problems encountered during reforms is not a bit overrated in recent literature. This paper presents the argument that it is not the leaders but the employees in the teams and working groups and the experienced organizational members in particular who are the real carriers of reforms. It goes through the recent and older theoretical literature as well as through known empirical research regarding the matter and suggests that mainly co-workers are able to provide reform in terms of content, direction and practical solutions. The conclusion is that leadership is indeed an overrated factor in explaining reforms. The emphasis on leadership disregards an old-fashioned but perhaps still relevant concept, namely that working groups/project teams are often self-regulating, despite what leaders believe. Although empirical research taking organizational tenure into account is scarce and scattered, there is some evidence that the communities of practice are important for conserving, changing and developing organizational values and norms.
\end{abstract}

In consequence, theorizing about reforms and especially the implementation thereof needs to pay more attention to horizontal relations in the organization - the role of colleagues and especially the role of experienced organizational members.

Keywords: leadership, employee engagement, administrative reform.

1 Associate Professor, University of Gothenburg, Sweden; E-mail: iwona.sobis@spa.gu.se

2 Dr., consultant, Patom, Netherlands; E-mail: patom@planet.nl

3 Professor, Radboud University Nijmegen, Netherlands; E-mail: m.devries@fm.ru.nl 


\section{Introduction}

According to American diplomats in their embassy documents sent to Washington, as released by Wikileaks (2010), the president of an Asian republic received a small "boat" of approximately 60 million US \$ in exchange for concluding a contract for the construction of a harbor, a factory and some infrastructure; a "boat", because he wanted a yacht comparable to that of Abramovich. The president was not satisfied with just the boat. He also asked for the employment of a Swedish crew. When the employees refused the job, he made it clear that it was an offer they could not refuse and confiscated their passports and diplomas. In addition, he asked for four other employees.

It was the same president who fired his security officer because a cat crossed the road while he was on his way to his dacha. The cat's crossing could have been an attack on his life. A car driver, who thought he could cross the road before it would be passed by the president, was heavily beaten by security forces and got 25 years imprisonment. Similar stories, true or not true, were released by Wikileaks at the end of November 2010 and address the presidents of Italy, Russia, Belorussia, Kazakhstan, Azerbaijan, Poland, Egypt, Libya and Hungary and other countries. The stories are similar in the sense that the political leaders in charge are judged as not being too intelligent, that they are prone to becoming rich by corrupt and fraudulent behavior and that they are interested in improving "their" administration in name only.

How does this ugly picture fit the idea, central to the study of Public Administration that we have to put our faith in leadership in order to accomplish improvements, public-administrative reform and the like?

For long, leadership has been a crucial concept in the study of Public Administration, and in recent years, it was even presented as a panacea. Successful reforms depend on good leadership. Also outside this discipline, leadership has been argued to be inevitable, more or less effective, and lately even to be determinative for public-administrative reform.

The reader will undoubtedly wonder whether the discussion above is not disturbed by missing the distinction between societal/political and organizational leaders. Whereas the former are (elected) politicians, the latter are directors and, in public administration, appointed officials. The former are often well-known to the public, the latter mostly operate backstage, at least in public administration. Their functions differ as well as their motivation to do the job (Page 1985, 2007), making the former qualify as real leaders, whereas the latter are seen as managers. This suggests that research making the distinction between leaders and managers is highly important (cf. Jacobsen and Thørsvik 2008); leaders are visionaries who can communicate their vision to other employees, they have the capacity to inspire and motivate others to work, they are innovators who promote changes and development, 
they want to, and can, share power with others, they are authentic, engaged, have intuition, focus on people, inspire trust, have a long-term perspective, are analyzers, challengers of the status quo, do the right things. Managers, instead, are looked upon as administrators, responsible for planning and dividing labor, they are implementers, copyists, aim at maintenance, have a keen eye for systems and structures, rely on control, have a short-term perspective, accept the status quo, do things right.

Such differences are -to say the least - not always taken into account in the major literature on leadership, which just defines leaders as people at the top of the hierarchy, and emphasizes the need for organizational leadership comparable to societal-political leadership. The modern literature on leadership differs from the classic literature on this subject. Organizational leadership in the classic definition could be divided into different types of leadership, that is task-oriented or peopleoriented, change-oriented or conservative leadership (Terry 2002), whereas in the modern definition, the latter are circumscribed as "managers" who, compared to leaders, frustrate organizational change. From a normative point of view, they are expected rather to act as leaders, because in society and in organizations, the emergence of leadership is inevitable, the features of leadership do make a significant difference, and if there is administrative reform, much if not all depends on leadership. At least that is the theory.

This paper critically assesses these theories and argues that leadership is an overrated concept, not half as important for making administrative changes happen, for making organizations effective and efficient, as co-workers of an organization are. The argument in this paper is that although it might be unavoidable that organizations have leaders or at least managers, it is also undoubtedly the case that leaders vary in their leadership qualities, as being people-oriented or task-orientation. However, there is not much evidence that leaders are the determining factor in inducing and achieving organizational change. The core of our argument is that alternative explanations of reform processes are available in particular by switching the focus from leadership to an organization as communities of practice in the sense of Wenger (1998).

This paper is structured in the following way: we first present an overview of theories about the role of leadership, the concept of leadership and the way it evolved through time and then identify the counterarguments for emphasizing leadership as the driving force behind organizational change. Subsequently the paper gives an overview of empirical research about reforms that illustrates the role of experienced organizational members as a factor to be taken into account.

\section{Three traditions in leadership theory}

Leadership theories are as old as the existence of leaders, and it is impossible to give a complete overview in just one paper. When searching for the word "leadership" 
on Google on 12 February 2011, the concept of leadership gave us approximately $198,000,000$ results in 0.12 seconds. Therefore we do not even attempt to be exhaustive. This section is only meant to provide a concise overview of three traditions in leadership theory.

The first tradition argues for the inevitability of leadership. Whenever people unite or organize, leaders are bound to enter the stage. Basically leadership is a keystone in the explanation of the relation between the individual and the collective. The leader is the mediator between the two levels. Very explicitly, this can be found in the role of the emperor in the Chinese tradition.

The second tradition investigates the characteristics leaders need to achieve results or successfully bring about change. It addresses, for instance, the differences between task- and people-oriented leaders.

The third tradition, which emerged more recently, poses that leadership is not only inevitable, but also argues for the indispensability of leadership for bringing about structural changes. It even argues that leadership is the determining factor in public administration reform, i.e. not only a necessary factor but also a sufficient factor. Everything in the organization seems to rely on its leadership.

It is this third stream of thought on leadership this paper challenges. However, in order not to be depicted as anarchists or utopians, that is in order to specify exactly what it is that is challenged in leadership theories and what is not, a concise expose of all three streams and their critics is needed before we take up our argument.

Ad 1: Many scholars have written about the inevitability of leadership, and this tradition is a long one. It can be argued that this tradition even started in ancient Sumer (4000 BC), as there are indications that the city-states had a strong government organization making mass production possible and profitable. The first king of Sumer is said to have emerged after a huge flooding, indicative for the need of leadership and organization to counter such natural disasters. Since then, every civilization has known social stratification and leadership. In Europe, Lovejoy noted that this is the case, because the state of nature is behind us and thus also the juristic state of nature, characterized by the absence of any but the "natural government of family and clan" (Becker and Barnes 1938, 426). The discontent of people with (political) leaders departs from the idealistic, but hardly realistic, idea that a life far simpler and less sophisticated is a more desirable life because our prehistoric progenitors lived a happier and more virtuous life (ibid., 424). Much later, Hobbes argued for the necessity of political leadership and what he called a "Leviathan". The much quoted part of his famous book "Leviathan" tells us that in society in the natural state of mankind,

there is no place for industry; because the fruit thereof is uncertain: and consequently no culture of the earth; no navigation, nor use of the commodities that may be imported by sea; no commo- 
dious building; no instruments of moving and removing things as require much force; no knowledge of the face of the earth; no account of time; no arts; no letters; no society; and which is worst of all, continual fear, and danger of violent death; and the life of man, solitary, poor, nasty, brutish, and short

(Hobbes 1651, ch. XIII).

In the $19^{\text {th }}$ and $20^{\text {th }}$ centuries, political philosophers like Bagehot, Mosca, Pareto and Michels argued similarly that the masses have to accept that they are led by a minority and have to follow the idea of state and nation, that they have to accept a political formula in which leadership is central, that even in socialist organizations - emphasizing equality - there is a tendency towards oligarchy, because of the division of labor, the need for technical expertise and the success in elections. Idealistic notions of democracy as described by Aristotle would be false, because democracy can exist for the people, of the people, but never by the people (Michels). The main arguments have always remained the same: leadership is an inevitable element of organization and unison in order to counter threats and to protect property rights; it is needed for successful production and socio-economic development. This approach mirrors the Christian tradition of leadership by the anointed king.

It is in this tradition that much research has been done into entrance problems (who can become a leader?) and the homogeneity of leadership with its matching terminology of elitism, pluralism, autocracy and democracy, sometimes summarized as the three C's: Consciousness, i.e. its esprit de corps, Coherence, i.e. its recruitment, and Conspiracy, the community in thinking (cf. Raadschelder 2003).

The inevitability of leadership has been challenged to no avail in, for instance, anarchism, a word derived from the Greek anarchos, meaning "without rulers", propagated in ancient times in Taoism by Liezi and later on in Europe by the Jacobins, Rousseau, Godwin, Proudhon, Kropotkin and in the USA by Tucker, Warren, Goldman and Berkman. Their belief in either complete liberty (Rousseau), the spread of individual knowledge and the subsequent redundancy of state power (Godwin), the organismic system of society with its inherent harmonious development towards perfection (Comte), the evolution of man towards a state of perfect adaptation involving a reduction of conflicts and thus less need for hierarchy (Spencer), or a system with public ownership of means of production and democratic control of all organizations without any government authority (Bakunin), however, seems, until now, utopian and will therefore be discarded in this paper (cf. Becker and Barnes 1938).

Ad 2: Many books have also been written about characteristics of good leadership. The lessons of Confucius already concentrate on this question. Relevant is his distinction between normative good leadership and leadership in practice. 
Empirical studies and theoretical models provide us with some elementary knowledge about the major trends and tendencies today. From the beginning, researchers were looking for the best leadership practices that essentially could contribute to achieving organizations' major objectives, i.e. a high level of productivity and efficiency. This started with the writings of Frederic Winslow Taylor in his famous book The Principles of Scientific Management (1998). He proposed a scientific method - optimizing - to provide leaders, in his words managers, with the elementary tools to train workers to make them work in the "best" way. Well-trained workers were expected to become as productive as possible and to be satisfied with their working conditions at the same time.

In the middle of the $20^{\text {th }}$ century, social scientists developed "great man" theories focusing on leaders' traits and personalities. Stogdill (1948) showed in his review based on 124 trait studies between 1904 and 1947, and his later review from 1974, which was based on 163 studies between 1948 and 1970, that a consistent set of traits guaranteeing a successful leading organization is missing. His research helps to understand how individuals' traits can influence the impact of leadership.

Still later, regarding studies about leaders' personalities, it proved that different situations demanded different behaviors from leaders. Thus, a shift of the leadership paradigm was obvious. Scholars started to address leaders' activities, i.e. what they really do in everyday practice. Famous is the thesis of Henry Mintzberg (1973) that structural conditions determine managerial (leadership) behavior. The next step was a scholarly interest in leadership styles, their capacity to adapt their style to changing situations and researchers' interest in the consequence of changes within the organizational environment for leadership. During the last two decades, leadership studies make clear distinctions between leaders who "do the right things" and managers who "do things right". In this tradition, we can identify two types of leadership research (cf. The Michigan Leadership Studies, The Ohio State Leadership Studies, McGregor's Theory X and Theory Y, Blake and McCanse's Leadership Grid, cf. Rainey 2009):

- Psychological studies about leaders' traits and personalities; the purpose is to judge the quality of leadership to characterize good leaders.

- Studies about leaders' behavior; these theories provide us with pragmatic ideas how to get the best work-result from employees. This type represents theories about leadership styles, situational leadership, contingency theory and team leadership, especially distinguishing people- and task-oriented leaders and promoting a combination of the two.

According to Fiedler, a leadership trait may be very important in one specific context, but not in another (Fiedler 1964). This depends on the structure of tasks and the power of a leader, but also on the type of staff, the history of the business, the culture of the business, the quality of the relationships between leaders and their 
followers, the nature of the changes needed and the accepted norms within the organization. With this in mind, Hersey and Blanchard therefore developed the socalled Situational Leadership Theory, in which the nature of the task in terms of uncertainty and the nature of the followers in terms of their maturity are central in defining the needed type of leadership (Hersey and Blanchard 1979, 1996). According to them, it is not leadership itself that determines the success and productivity of an organization, but the fit between the characteristics of leader and what is needed to be given, the specifics of the context, and the people, i.e. followers, the leader has to work with.

Ad 3: More recently, one can witness a third stream of thought, possibly becoming a research tradition in which the tasks and crucial position of leaders are emphasized. Leaders are seen as determinative forces of organizational and societal change and reform. This stream involves studies on leaders, who are viewed as essential in giving the organization direction and meaning, and leaders as being central in bringing about organizational change (institutional leadership, transactional leadership, transformative leadership) (Northouse 2004; Yukl 2010; Jacobsen and Thørsvik 2008). This research focuses on studies about leadership tasks; theories that focus on leadership roles, their formal position and authority, interpersonal roles, information roles and decision-making roles. One of the claims is that organizational change occurs if and only if there are transformational leaders who 1) have charisma, i.e. leaders who provide vision and a sense of mission, instill pride, gain respect and trust; 2) are inspirational, i.e. who can communicate high expectations, use symbols to focus efforts, express important purposes in simple ways; 3 ) provide intellectual stimulations, i.e. promote intelligence, rationality and careful problem solving; and finally 4) are sensitive to individualized consideration, give personal attention, treat each employee individually, coach, and provide subordinates with advise. For instance, Eisenbach and Watson (1999) argue:

The importance of leadership to the change management process is underscored by the fact that change, by definition, requires creating a new system and then institutionalizing the new approaches.... change management depends on leadership (80).

In this tradition, the role of leadership has become the all-explaining factor and a tradition in which the necessity of leadership to counter threats has become a single-factor explanation of change by the organizations' leadership to initiate, steer and implement societal and organizational reforms, as Quinn (1996) argues: "Empowered leaders are the only ones that can make real change in the organization" (no page numbers). They are the ones who provide a vision. According to Minzberg (1992), leadership may be thought of as the soul of organizational change. Such a view upon leadership is especially found in theories on transformational leadership. In this view, leaders accomplish organizational change by taking care of the process as in the process-based model of leadership, which draws upon the procedural jus- 
tice literature to hypothesize that leaders motivate their followers to accept change by exercising their authority via fair procedures (Tyler and Cremer 2005); by overcoming organizational resistance to change (Bovey and Hede 2001); by making the organization ready for change, (Holt et al. 2007); by changing the organizational culture (Schein 1985); by learning from organizational change in other organizations, cf. Sevón (1996), who argued that every theory of organizational change must take into account the fact that leaders of organizations watch one another and adopt what they perceive as successful strategies for growth and organizational structure (60-61); and by achieving results (Müller and Turner 2007). As Burke and Litvin (1992) argues: "in large scale or total organizational change, mission, strategy, leadership, and culture have more 'weight' than structure, management practices, and systems" (528).

The third tradition is not independent of the first two. From the first tradition, it follows that leadership is inevitable, and therefore, it must play a role in reform. The second tradition uses the idea that research aimed at explaining the varying success of reform must concentrate on the qualities of leaders during such reforms, and the third tells us that we only have to look at leadership.

\section{Critical reflections with regard to the third tradition}

Although all three traditions have known their critics, this paper will only challenge the claims of the third stream "Leaders are seen as determinative forces of organizational and societal change and reform." We address studies on leaders, where they are seen as essential for change and reform, argue for the limits of leadership and present some arguments that challenge especially the last notion.

Even without becoming an anarchist, the role of leaders can be seen as limited. The literature emphasizing the importance of leadership itself is sometimes contradictory as Higgins argued in his review of Schein's work on culture and leadership:

Despite [Schein's] frequent and repeated emphasis on the power of leadership, a great deal of the substance of his study is taken up with detailing the limits of leadership when dealing with organizational culture. These limits are in part internal: the leader doesn't know what he wants, and acts in contradictory ways; and partly interrelational. In the end, the key point that emerges from a careful reading of Schein is one that works against much of his general claims. It is the simple fact that the leader cannot be regarded as being outside the process, and able to use the organization as if it were an instrument of his will; he (as pre-feminist writing has it) is better regarded as one of several interacting elements (Higgins 2007, 102). 
Similar criticism was uttered by Jackson, who argued in 2005 - quoting a critical essay by Meindl, Ehrlich and Dukeric of 20 years earlier - that the concept of leadership still is not understood in a way that is intellectually compelling and emotionally satisfying. The concept of leadership remains elusive and enigmatic. (Jackson 2005, 6)

But also in practice, the all encompassing role of leadership can be disputed. One can point for instance to the increasing number of case studies on the success of self-managed teams, indicating the limited role of leadership (managing by walking around). According to Yukl (2010), several distinct types of groups and teams can be found in organizations, varying in their dependence on leadership. He points to differences between working groups and teams. The working group consists of members belonging to various work units or small subunits (departments, sections) within an organization. They perform a common functional task e.g., in production, research, or sales "under the supervision of an appointed manager" (Yukl 2010, 356). Each member of the working group is working alone and is independent of other colleagues in the group. The members of the working group only need some kind of co-ordination of activities to reach the purpose of the organization. This type is known under the name of "coaching group". A team is also a small task group consisting of team members who do their job independently. The members play a complementary role in relation to each other, and in this sense, they are dependent on each other; the members' different skills are necessary to reach the major objectives of team. The emphasis in this theory is on the important role played by colleagues or co-workers rather than by leaders. Several types of teams can be found, and they vary in their dependence on leadership. There are functional work teams, in which the leader has a formal position; cross-functional teams, i.e. temporary teams created for a specific project/program, to which the formal leader is usually appointed by higher management (cf. Cronin and Weingart 2007); self-managed teams (or semi-autonomous groups), in which the team itself is responsible for a specific product or a special service. Here the team's internal leadership role is based either on free election by the team members or "the position may be rotated among different members on a regular basis (e.g., quarterly or annually)" (Yukl 2010, 369); virtual teams, in which the members are geographically separated and the members seldom meet face-to face, sometimes never, because most communication takes place through ICT-technology (e-mail, video conference, telephone, fax etc.) and in which leadership is something entirely different in its challenges (Yukl 2010, 370); and top executive teams or "office of the chairpersons", gathered around the CEO and other top executives sharing strategic leadership in order to make better strategic decisions (see, e.g., Bantel and Jackson 1989).

Such variance in organization points to the need for theories about followers, or rather co-workers, instead of theories on leadership, and these have indeed been developed. Too often, it is taken for granted that leaders exercise power, authority, 
and influence others (Machiavelli 1984; Kieffer 1984; Jacobsen and Thørsvik 2008; Yukl 2010). However, the dependence of leaders on their followers might be as large as the dependence of followers on their leaders. Leaders can only be seen as determinative if there are only passive followers, but often followers vary in their degree of complacency. An overview of the literature shows that our knowledge about followers, their characteristics and their importance for organizations and even for leaders' existence is still limited.

Returning to the idea of reform, we know that the greatest difficulty therein is in changing the culture, the organizational behavior, which is often out of the leaders' hands. The role and influence of the co-workers from the point of view of organizational culture and culture-change is probably more important and can be analyzed by using the concept of "communities of practice", as introduced by Wenger in 1998. Communities of practice are groups in organizations with the same experience and history in learning. From this research, one can conclude that followers are not just individuals, but also communities with their own position regarding reforms.

On these communities, theories such as Follower Attribution and Implicit Theories can be applied. The most popular theory grouping organizations in this sense is the Leader-Member Exchange Theory [LMX], which is, unfortunately, first and foremost descriptive in character and has some weaknesses limiting its explanatory power. This theory is also ambiguous about the nature of the exchange relationship. It does not explain how the dyadic relations develop over time, "how the leaders' different dyadic relationships affect each other and how differentiated relationships affect overall performance by the leaders' work unit" (Yukl 2010, 239).

Lord and Maher (1991) and Dasborough and Ashkanasy (2002) argue that leaders who can delegate power and have personal interest in making some changes within their organization are usually perceived as competent. Regarding actions, followers ascribe competence especially to those leaders who take direct actions and are successful in taking organization out of a deep crisis. In contrast, insincere or self-sacrificing leaders are perceived as manipulative, and they are not appreciated by followers. Some theories in this field explain how followers can actively influence their work role in relationship with the leader, especially if s/he is perceived as "one of them" (Hogg, Hains and Mason 1998), or in other words: member of the same community.

Notwithstanding the research pointing to a dependence not of followers on leaders, but of leaders on their followers, and notwithstanding the research pointing to the impossibility of leaders to change the environment in which they operate and the need for adaptation by leaders in order to achieve a fit between their traits and the characteristics of the environment, the last two decades have seen a fast-growing literature on the almost determinative role of leadership on organizational and societal change (cf. Yukl 2010; Raadschelder 2003; Montana and Charnov 2008). 
Pointing to the need for visionary leadership, ethical leadership, transformational and ideational leadership etc., the third research tradition assumes that leadership is a kind of panacea and that there is an absolute necessity for organizational change. Criticism on these ideas is, for instance, found in theories about leadership substitutes. These theories describe how the nature of the task, the distance between leaders and followers, the professionalism of followers make a hierarchical leader less important for their everyday work. Kerr and Jermier (1978) belong to the first researchers in this field. They identified substitutes and neutralizers for supportive and instrumental leadership. "Substitutes" concern characteristics of subordinates, i.e. their skills, knowledge and competence when doing their work as professionals, e.g. medical doctors, airline pilots, academic tutors and other professions that do not require any supervision, and who do everything possible to avoid controls. "Substitutes" for supportive leadership make leader behavior unnecessary and redundant, because employees know the organization in which they are working very well. Such experienced organizational members know the organizational structure and work division, they and understand their own duties and roles. They are highly motivated and satisfied with the responsibility they have. "Neutralizers" are another type of substitutes for instrumental leadership. "Neutralizers" concern the characteristics of the tasks, i.e. simplicity, repetitive tasks that subordinates can learn without extensive training or direction, especially in the situations when feedback comes immediately from the task or from the informative system of organization that subordinates can check themselves, e.g. by an information system or the Internet. In such a system, the leader becomes redundant, because s/he is devoid of opportunities to provide rewards or punishment for subordinates' respectively "good" or "bad" performance, and without any authority to influence employees' performance. Moreover, in organizations where intern regulations and policy documents dominate, a leader becomes redundant because the work processes become inflexible. Thirdly, geographical dispersion, a quite common phenomenon for international teams, makes supportive and instrumental leaders much weaker and sometimes even redundant (Yukl 2010, 176ff). Rules and company policies, as well as geographical dispersion, routines and professionalism, work either as neutralizers or substitutes to leadership.

The above argues that perhaps leadership is inevitable, but does not have to be seen as a panacea. Probably it is itself dependent on, or even encapsulated within, the specific characteristics of the context with regard to the environment in which the organization is situated, the task to be performed and the traits of the employees who have to do the work. This implies that the leadership theories that have been developed recently might well overrate the impact of leadership and miss the point in explaining organizational change. It is only to a limited extent that leadership can steer, change and implement organizational changes. Often leadership is embedded within an organization's formal structure and also in its organizational culture. Organizational culture with its basic assumptions, values and norms for behavior can 
support or block the fulfillment of major objectives, and leaders may give a general tone to its development, but they do not have much influence on the emerengence of sub-cultures within the organization. Organizational culture and sub-cultures can be functional as well as dysfunctional for an organization, and organizational culture together with the formal organizational structure might have more impact on the nature of reforms than leadership. Leadership is embedded in the organizational formal structure, culture, and development, but also in the environment of the context with many stakeholders, its uncertainty and dynamics. This implies that in theory, it might well be the case that administrative reforms more often befall the leadership than being initiated, steered and implemented by leadership. Furthermore, leaders are often not the ones who initiate change and reform, but rather act as conservators (Terry 2002). In the same line, we read in the classical Chinese theory on management theory; "The manager is as the northern star. His role is not to move but to be the orientation point for others, circling around the pole star" (see: e.g. Ong Hean-Tatt (1994), who uses this image also found in chapter II of the Analects).

Of course, the question that immediately emerges is whether there are alternative explanations and theories about the question of what determines the success of organizational change and administrative reform and whether these live up to their expectations. The next section will address one of these theories, the theory on leadership substitute theory.

\section{The role of experienced organizational members in organizational reform}

If the theory on leadership substitutes is valid, and distance between communities of practice and leaders, task-specificity, features of the employees, the limitations in possibilities to reward and punish employees, the uncertainty and dynamics of the organizations' environment and the often conservative trait of leadership do limit and neutralize the impact of leadership on reforms and even make leadership redundant, it becomes almost self-evident that the theory on organizational change has to incorporate other actors than the leadership in its explanation for organizational change or the stagnation of change (see Rubinstein and van den Berg 1992, 188).

Leadership substitute theory implicitly suggests looking for actors who are close to the work floor, who have insight in the specificities of the task to be performed, who know the needed and present qualities of the staff in terms of professionalism (knowledge, skills and attitudes), who have experienced changes in the fit between the organizational structure and its more or less dynamic and uncertain environment, and who know what kind of change is needed, what change has been tried before, and the changes that failed and which were successful. The only ones 
in the organization fitting this description are the experienced organizational members, i.e. communities of practice. These actors do not only or necessarily include those who were promoted to senior levels, but especially those organizational members who have long-term experience, have a passion for what they are doing and are not eager to change their job for a better-paid management or leadership function. Perhaps the presence and characteristics of such experienced organizational members, their involvement in organizational change processes and the degree to which actual organizational change is congruent with their ideas about the right direction of this change, an organizational change perhaps even initiated by them, and certainly to be implemented by them, might well be more crucial for explaining the success of organizational change than is the impact of leadership.

First, it has been known for long that in public administration, reforms or other organizational changes, including incremental changes aimed at improving a current performance at hand, are more often forced upon the organization than independently initiated by its leaders (Lindvall 2010; Hallin and Siverbo 2010). State reforms representing a political will and ordered from the institutional level frequently take place due to a state's economic conjuncture. During periods of economic decline, such as the oil crisis in the 1970s or the banking crisis in the 1990s and the recent financial crisis, characterized, among others, by a decrease of GNP, huge unemployment and the increasing costs of public services, decentralization seems to be a solution for the national state that can no longer guarantee adequate public services itself. In such situations, the public sector often takes inspiration from the private sector to improve its external effectiveness and internal efficiency (productivity). The idea of New Public Management (NPM) caused the introduction of several modified market solutions in the public sector and found its expression in the decentralization of decision-making authority, creating internal systems leading to increasing importance of performance management, accountability and procurement (Hood 1995; Pollitt 1993; Almqvist 2006; Nemec 2010). This idea was spread very quickly in most European countries in many a public organization. Many public organizations neither initiated nor desired the changes in this direction, but it was forced upon them. With the benefit of hindsight, one can say that the NPM reforms were not initiated by individual leaders, but were forced upon them by the circumstances, enabled by a new theory and copied from other organizations.

Another factor, external to the organization, but becoming more and more important in judging the organizational performance, consists of the clients/customers and their needs. As a response, public organizations followed the logic of fashion - Client centering - and it is not so surprising that organizational and leadership theory addressed the solutions mentioned in these fashions.

Acknowledging that reforms often befall organizations and their leadership made scholars turn their focus on new phenomena deemed important for organiza- 
tional change, e.g. empowerment, power sharing, emphasizing working groups and teams, and starting to research not leaders, but followers and engaged employees (Northouse 2004; Jacobsen and Thørsvik 2008; Yukl 2010). This research has slowly but steadily contributed to our knowledge on the role of followers, employees, and especially those engaged employees that are seen as an alternative to leadership.

One quite interesting example in this regard is the Scandinavian theory on Medarbetarskap developed by Swedish scholars (Hällstén and Tengblad 2006; Tengblad et al. 2010). According to Stefan Tengblad, the English term followership seems to be the most adequate translation for medarbetarskap. However, other terms like employeeship or engaged employeeship are closely related and seem to be adequate, too. The concept of engaged employee/follower is interesting, because of its dual character. On the one hand, it specifies the question of how people explain their own relation to their employer, their own work and their colleagues (Tengblad $2010,20)$ On the other hand, this term points to a philosophy beyond the classic leadership theories, e.g. the focus on employees and traits ascribed to them, such as an active and responsible attitude towards work, learning processes and individual development. For instance, engaged employees take responsibility for community and cooperation. They are open to new challenges and often give support to others, be it as mentors (Douglas 1997) or socializers (Sobis and De Vries 2010). In other words, the theory about engaged employee/follower departs from "a vision of the working environment that combines efficiency and good performance with social responsibility, job satisfaction and well-being" (Tengblad 2010, 6).

This theory developed through four stages and alongside the general development of leadership theory. The first step addressed Democratic Leadership and Employment Development (1970s). In this theory, the leader consults and discusses with the staff how the work would be carried out in order to live up to the major objectives of organization. During this period, workers are expected to be engaged and involved but especially loyal in the process of organizational development. The second step is known as Corporate Culture and Work Motivation (1980s). Employers gradually realize that they are dependent on employees' commitment, motivation and initiative. Therefore, they create competitive and successful organizations trying to develop an organizational culture that brings about commitment and loyalty towards the organization among the employees. The third step is the Introduction of the Flat and Head Sparse Organizations (1990s). The mid-level managers and direct steering supervisors are replaced by personnel managers, who take responsibility for finance and human-resource management. The traditional supervisors transform into members of workgroups and teams. The main part of the responsibility is left to work-groups themselves. The managers are expected to show confidence and trust in their employees by not interfering in how they perform their daily work. Although such self-managing teams are growing in numbers; the self-governing groups generally do not perform as intended. Many problems regarding the performance in the workplace remain unsolved, the cooperation of working groups is 
often inadequate and managers' support for the working groups insufficient. The fourth, and until now final, step concerns Employeeship as Organizational Interactions (2000s); managers are more involved again but within the development of engaged employeeship. Employees are more than ever involved and engaged in work teams and the performance of work teams in relation to the performance of the whole organization. A combination of inspiring and competent leadership like transformative leadership and well-functioning working groups and teams with a good understanding of the whole organization are perceived as the most profitable solution for work organization (Tengblad 2010, 6-7).

Within this theory, Hällstén and Tengblad (2006) identify five forms of followership or engaged employees: (1) traditional followership, (2) organization-oriented followership, (3) group-oriented followership, (4) individual-oriented followership, and (5) leaderless followership, based on the idea that leadership is not a person or position. It is a complex moral relationship between people, based on trust, obligations, commitments, emotions and a shared vision of "good". Ethics is at the heart of all human relationships and consequently the relationship between leaders and followers (Hällstén and Tengblad 2006, 224).

Traditional followership is based on managers/supervisors who are in the center. They take responsibility for the organization's major objectives while employees perform their tasks. In colloquial terms: "managers think and employees do." One can observe a development of a strong we/they feeling. Employees play a passive role with hardly any attention to their satisfaction. Communication within the organization is unidirectional, i.e. by instructions from the top level.

In an organization-oriented followership, managers/supervisors usually delegate responsibility to employees, but the hierarchy concept is established at the central level, i.e. the degree of responsibility and autonomy is defined at the top level. In such organizations, the values, norms and practices are defined top-down. Thus, followers are told their responsibility within the system. In this system, the followers' performance and outcomes are closely monitored.

In the group-oriented followership, a strong emphasis is put on decentralization and management by objectives. Followers receive a large degree of responsibility and autonomy. The group itself decides about the content of activities and the group's responsibility for quality, economy and security when working.

Performance-oriented followership occurs when individuals take responsibility for their own activities understood as their professional role. Moreover, followers or engaged employees take responsibility for the project in which they are involved. Followers are seen as autonomous/independent, while management is generally weak. Managers are expected to coordinate activities, but not to steer followers or engaged employees in how they accomplish their tasks. 
The last form is leaderless followership. Followers or engaged employees perceive themselves as entrepreneurs or self-employed persons. The leaderless followership is quite demanding, because it demands constant self-development and development of the performance, especially with regard to the important projects for the organization. This type of followership implies the absence of hierarchical managers. In fact, managers only have a symbolic value and/or purely administrative role. The leaderless followership is typical of free professions like physicians, lawyers, university teachers (Hällstén and Tengblad 2006, 11).

It seems that the concept of leaderless followership or autonomous experienced and engaged employees is crucial for followership theory and is strongly related to our ideas about the limits of leadership for public-administration reforms. In comparison to leadership theories, it emphasizes the important role of experienced staff, because of its institutional memory of the organization's development, its regulations, directives, policy, task, but also the memory of previous reforms and how external relations with other stakeholders work in practice. They know the organization and the organizational environment very well. They can be catalysts but also blockades for successful reforms or organizational changes. Experienced and engaged employees have an internalized knowledge of what is working in practice, and what is not. In Nonaka's terms, they have knowledge that they can share by observing each other, verbally by mentoring, or by written instructions, or by a combination of all mentioned methods. Thus, experienced and engaged employees are deeply involved in organizational learning (Nonaka and von Krogh 2006).

This results in the proposal of an alternative causal model for the success of organizational change. In it, there are three crucial factors: the presence of experienced organizational members, their involvement in the change process, and the congruence between the content of organizational change and the opinions of these organizational members.

\section{Empirical support}

The above all sounds perfectly rational, but is there any empirical support for this theory? That will be discussed in this section. First, we address the question of whether the working groups and teams should be involved and subsequently why experienced organizational members are especially important.

Support is first found in the research on administrative reform, e.g. Golembiewski (1985) points to the huge probability of failure of reforms and attempts to change attitudes and behavior if the organizational structure remains hierarchical and does not support what is going on in working teams. B. Guy Peters, in his book Taking Stock, argues that there is a dilemma. On the one hand, the top of government (leadership) has to be involved and committed in order to make administrative reform succeed, on the other hand, it will not succeed unless this reform 
is "owned" by the lower echelons of organizations (Peters 1998, 80). He points to examples in Canada, where change imposed on civil service created resentment and resistance, while change involving civil servants appeared to be more acceptable to rank and file employees (Peters 1998, 82). That is the same conclusion as that reached by Sousa and Vala (2002), who pointed out that support for organizational change can be predicted on the level of the work floor and department, but not at the level of the organization as a whole. They conclude that support for change is especially determined by pride and respect in working groups. The reason is that "it is possible that the department and the work group may be particularly relevant groups for the individual and also that the supervisor may be seen, in this case, by organization members as a true representative of the department and the workgroup, but not of the organization as a whole" (Sousa and Vala 2002, 117). Evaluations show the same, e.g. Christopher Reichart evaluated the administrative reforms in Germany in the 1990s. He emphasizes the process and involvement of the administrative level and concludes on the positive side that "the reforms are 'bottom-up' reforms originating in administrative bodies themselves; they enjoy wide acceptance among administrative staff, who are generally extremely unhappy with the prevailing structures", but on the negative side also that:

... the attention paid to the interests of employees is too little and too late: the success of the reform is to a very large extent dependent on them being in possession of all the relevant information on what it involves, on their participation in decision-making on reforms, and on their continuing willingness to learn new skills and procedures. Very often employees are ill informed and are unable to cope with the speed with which reforms are implemented. In order to minimize risks to reforms, it is advisable to enter into a pact with staff representatives with regard to reform, which can then form the basis for close cooperation (Reichart 2001, 555).

This type of research is based on minimizing resistance to administrative reform, by departing from the work floor instead of top-down. The conclusion is that if one involved or empowered the working groups and teams in reform processes, one could avoid ending up in the kind of administrative reform Caiden talked about, 40 years ago, namely administrative reform as "the artificial inducement of administrative transformation against resistance" (Caiden 1969, 65) and to change it into administrative reform as "the induced systemic improvement of public sector operational performance" (Caiden 1991, 1).

Is there a special role for experienced organizational members? The evidence thereon is scarce and scattered, just because tenureship is often not taken into account in empirical analyses of administrative reform. However, Amis, Slack, and Hinings (2004) argue that it helps beginning the transformation process by changing "high-impact" decision-making elements of the organization first, because it 
helps to build momentum for the broader array of changes that follow. Xu Huang, Kan Shi, Zhijie Zhang and Yat Lee Cheung (2006) come close when they conclude that although "participative leadership behavior tended to make short-tenure employees feel competent and thus, more committed to an organization, such leadership behavior did not have a significant impact on competence as well as organizational commitment for long-tenure employees" (345). It is indicative that there are differences between organizational members based on their experience in the organization, and that especially experienced organizational members are somewhat immune to leadership in all its appearances. This is also the conclusion of Carr and Eagles: "Commitment must be fostered differently among new and experienced employees because their organizational perspectives are unavoidably dissimilar" (Carr and Eagles n.d., n.p.). On the downside, this is seen for instance in blockades experienced members pose for renewal. As Sabel (1995) described it: "In firms making the transition from the old production methods to the new, for example, skilled supervisors frequently reject solutions proposed by teams of less experienced employees as an insolent usurpation of their authority" (Sabel 1995, n.p.). On the positive side, there is much literature on mentoring, in which experienced organizational members guide, coach and train young organizational members. The effects thereof are described for instance in Douglas (1997). This research not only describes the effects of mentoring on the junior members, but also sees it as a condition inducing trust and respect on the side of the juniors, while on the side of the mentors, it results in pride, thus giving the mentors a special position in the organization.

Although we are sure we missed many a study important in this respect, we can conclude that experienced organizational members - not managers, but still professionals in working teams, that is -, their number, their role and their involvement might well be special factors for explaining the success of administrative reform.

\section{Conclusions}

As we were writing this paper, the revolutions in the Maghreb countries unfolded. The first part of Tunisia's revolution - the removal of President Ben Ali - succeeded. The same happened in Egypt with President Mubarak. The societal changes befell them. As political leaders, they did not exert any influence on these changes (even if they wanted them), and steering developments from the top was impossible. At first sight, it seemed to be an uprising of the young people being oppressed for years by these regimes. However, detailed analyses done by Al Jazeera pointed out the success was partly determined by the support they received from experienced friends out of former Yugoslavia. For years, the Egyptian young people seemed to have had the support and advice of people previously involved in the revolution in Serbia 
who succeeded in the removal of Milosevic in 2000. They told them about strategy and tactics. This paid off. They were successful in bringing about change.

This paper is about such changes, not only in society, but also in organizations. How to explain successful organizational and societal reform?

The first recommendation given until now in Public Administration Theory is that transformative leadership is needed. Leadership is not only thought to be inevitable, but also to be indispensable for bringing about successful reforms. The main theoretical and practical problems conducive to failed reforms are thought to be posed by the qualities of leaders and the education of potential transformative leaders. In this paper, we presented a concise discussion about these theories and made critical remarks about the validity of especially the latter assumption, that leadership is a panacea. The main observation is: "No leadership without followers." Alternatives for the standard theory start from describing the role of communities of practice, which might have a more important role in successful reform then managers. We illustrated our point by using the leadership substitution theory.

In the end, this resulted in a proposal to look at the impact of other actors in the organization, i.e. the experienced organizational members as can be identified in communities of practice. They are the more or less engaged employees taking responsibility for community and cooperation, open to challenges and often giving support to others, be it as mentors or socializers.

The implication is that the success of organizational change may well be more dependent on the presence and characteristics of experienced organizational members, their involvement in the change process, and the congruence between the content of organizational change and the opinions of these organizational members than on leadership by either managers or politicians.

Accepting this conclusion, a reorientation of research on reform processes in public administration is needed. Such research is needed, first because we hardly found any research taking the experience of the organizational members into account as a possible determinative factor for the success of administrative reform, and such research could enhance our knowledge about explaining successful reforms. Second, a need for further research in this direction is felt, because - although there is no one-to-one relation between age and organizational experience - within a couple of years, many of the most experienced organizational members will retire. The question is what this implies for administrative reforms in the years after. The lack of institutional memory - needed to signal that this or that reform just reinvents the wheel - and the loss of pride, respect, loyalty and commitment might well increase the number of reforms, but simultaneously endanger the success-rate of such administrative reform. 


\section{References}

Almqvist, R. 2006. New Public Management: Om konkurrensutsättning, kontrakt och kontroll. Malmö: Liber.

Amis, J., T. Slack and C. R. Hinings. 2004. "The Pace, Sequence, and Linearity of Radical Change." The Academy of Management Journal 47 (1), 15-39.

Ashkanasy, N. M. and C. Gallois. 1994. "Leader Attributions and Evaluations: Effects of Locus of Control, Supervisory Control, and Task Control." Organisational Behaviour and Human Decision Processes 59, 27-50.

Bantel, K. A. and S. E. Jackson. 1989. “Top Management and Innovations in Banking: Does the Composition of the Top Team Make a Difference?" Strategic Management Journal Special Issue: Strategic Leaders and Leadership 10 (S1), 107-124.

Becker, H. and H. E. Barnes. 1961 [1938]. Social Thought from Lore to Science. New York: Dover.

Bell, B. S. and S. W. J. Kozlowski. 2002. "A Typology of Virtual Teams, Implications for Effective Leadership." Group Organization Management 27 (1), 14-49.

Bovey, W. and A. Hede. 2001. "Resistance to Organisational Change: The Role of Cognitive and Affective Processes." Leadership \& Organizational Development Journal 22 (1), 372-382.

Burke, W. W. and G. H. Litwin. 1992. "A Causal Model of Organizational Performance and Change: A Causal Model of Organizational Performance and Change." Journal of Management 18 (3), 523-545.

Caiden, G. E. 1991. "What Really is Public Maladministration?” International Journal of Public Administration 37 (1), 1-16.

Caiden, G. E. 2007 [1969]. Administrative Reform. Chicago: Aldine.

Carr, D. E. and P. E. Eagles. n.d. The Commitment Gap: Lessons Learned about Employee Commitment in the Parks Canada Agency. Available at van uwaterloo. ca (last accessed 5 June 2012).

Cohen, S. G. 1991. Teams and Teams Work: Future Directions. Los Angeles, Ca: Center for Effective Organizations, University of Southern California.

Cronin, M. A. and L. R. Weingart. 2007. "Representational Gaps, Information Processing, and Conflict in Functionally Diverse Teams." Academy of Management Review 32 (3), 761-773.

Czarniawska, B. and G. Sevón (eds). 1996. Translating Organizational Change. New York: Walter de Gruyter. 
Dasborough, M. T. and N. M. Ashkanasy. 2002. "Emotion and Attribution of Intentionality in Leader-Member Relationships." The Leadership Quarterly 13, $615-634$.

Dionne S. D., F. J. Yammarino, L. E. Atwater and L. R. James. 2002. "Neutralizing Substitutes for Leadership Theory." Journal of Applied Psychology 87 (3), 454-464.

Douglas, C. E. 1997. Formal Mentoring Programs in Organizations: An Annotated Bibliography. Greensboro, North Carolina: Center for Creative Leadership.

Edmondson, A. C., M. Roberto and M. Watkins. 2003. "A Dynamic Model of Top Management Team Effectiveness: Managing Unstructured Task Streams.” The Leadership Quarterly 14, 297-325.

Eisenbach, R. K. and R. P. Watson. 1999. "Transformational Leadership in the Context of Organizational Change." Journal of Organizational Change Management 12 (2), 80-89.

Fiedler, F. E. 1964. "A Contingency Model of Leadership Effectiveness." In L. Berkowitz (ed.). Advances in Experimental Social Psychology 1, 149-190.

Finn, R., G. Currie and G. Martin. 2010. “Team Work in Context: Institutional Mediation in the Public Service Professional Bureaucracy." Organization Studies 3 (08), 1069-1097.

Golembiewski, R. T. 1985. Humanizing Public Organizations. New York: Lomond.

Hallin, B. and S. Siverbo. 2010. Styrning och organisering inom hälso- och sjukvård. Lund: Studentlitteratur.

Hällstén, F. and S. Tengblad. 2006. Medarbetarskap i praktiken. Lund: Studentlitteratur.

Hersey, P. and H. K. Blanchard. 1996. "Great Ideas Revisited: Revisiting the LifeCycle Theory of Leadership." Training \& Development Journal 50, 42-48.

Hersey, P. and H. K. Blanchard. 1979. "Life Cycle Theory of Leadership." Training and Development Journal 33, 94-106.

Higgins, J. 2007. "Institutional Culture as Keyword." Triennial Review 3, 150-186.

Hobbes, T. 2009 [1651]. The Leviathan. Oxford: Oxford UP.

Hogg, M. A., S. C. Hains and I. Mason. 1998. "Identification and Leadership in Small Groups: Salience, Frame of Reference, and Leader Stereotypicality Effects on Leader Evaluations." Journal of Personality and Social Psychology 75 (5), 1248-1263.

Holt, D. T., A. A. Armenakis, H. S. Field and S. G. Harris. 2007. "Readiness for Organizational Change: The Systematic Development of a Scale." Journal of Applied Behavioral Science 43 (2), 232-255. 
Hood, C. 1995. "The New Public Management in the 1980s: Variations on a Theme." Accounting, Organization and Society 20 (2-3), 93-109.

Jackson, B. 2005. “The Enduring Romance of Leadership Studies." Journal of Management Studies 42 (6), 1311-1324.

Jacobsen, D. I. and J. Thørsvik. 2008. Hur moderna organisationer fungerar. Lund: Studentlitteratur.

Kerr, S. and J. M. Jermier. 1978. "Substitutes for Leadership: Their Meaning and Measurement." Organizational Behavior and Human Performance 22, 375403.

Kieffer, C. H. 1984. “Citizen Empowerment: A Developmental Perspective." Prevention in Human Services 3 (2), 9-36. Available at http://pdfserve.informaworld. com/879919_731377804_904473187.pdf (last accessed 16 February 2011).

Leisink, P. 2003. Reform of Public Bus Transport and Staff Participation and Involvement: Public Law and the Modernizing State. European Group of Public Administration Annual Conference Oeiras, Portugal, 3-6 September 2003. Available at http://soc.kuleuven.be/io/egpa/HRM/lisbon/leisink.pdf (last accessed 18 February 2011).

Lindgren, L. 2008. Utverderingsmonster: Kvalitets- och resultatmätning $i$ den offentliga sektorn. Lund: Studentlitteratur.

Lindvall, J. 2010. Verksamhetsstyrning: Från traditionell ekonomistyrning till modern verksamhetsstyrning. Lund: Studentlitteratur.

Lord, R. G. and K. J. Maher. 1991. Leadership and Information Processing: Linking Perceptions and Performance. Boston: Unwin-Hyman.

Machiavelli, N. 1984 [1513]. The Prince. London, Random House, Bantam books.

Mintzberg, H. 1992. “Cycles of Organizational Change." Strategic Management Journal 13, 39-59.

Mintzberg, H. 1973. The Nature of Managerial Work. New York: Harper \& Row.

Montana, P. J. and B. H. Charnov. 2008. Management: Leadership and Theory. Hauppauge, New York: Barron's Educational Series.

Müller, R. and J. R. Turner. 2007. "Matching the Project Manager's Leadership Style to Project Type." International Journal of Project Management 25 (1), 21-32.

Nemec, J. 2010. "New Public Management and its Implementation in CEE: What Do we Know and where Do we Go?" NISPAcee Journal of Public Administration and Policy 3 (1), 33-54.

Nonaka, I. and G. von Krogh. 2006. "Organizational Knowledge Creation Theory: Evolutionary Path and Future Adavance." Organization Studies 27, 11791208. 
Northouse, P. G. 2004. Leadership: Theory and Practice. Thousand Oaks, London and New Delhi: Sage.

Ong Heat-Tatt. 1994. Secrets of Ancient Chinese: Art of Motivation. Kuala Lumpur, Malaysia: Pelanduk Publications.

Orsburn, J. D., L. Moran, E. Musselwhite and J. H. Zenger. 1990. Self-Directed Work Teams: The New American Challenge. Homewood, IL: Irwin.

Page, E. C. 2007. "Middle Level Bureaucrats: Policy, Discretion and Control." In Jos Raadschelders et al. (eds). The Civil Service in the $21^{\text {st }}$ Century. Houndmills: Basingstoke Palgrave, 152-168.

Page, E. C. 1985. Political Authority and Bureaucratic Power. Knoxville: University of Tennessee Press.

Peters, B. G. and D. J. Savoie. 1998. Taking Stock: Assessing Public Sector Reforms. Quebec: Canadian Centre for Management Development.

Pollitt, C. 1993. Managerialism and the Public Services. Oxford: Blackwell.

Quinn, R. E. 1996. Deep Change: Discovering the Leader Within. San Fransisco: Jossey-Bass Publishers.

Raadschelders, J. C.N. 2003. Government: A Public Administration Perspective. New York: M. E. Sharpe.

Rainey, H. G. 2009 [1992]. Understanding and Managing Public Organizations. $4^{\text {th }}$ edn. San Francisco: Wiley/Jossey-Bass.

Reichard, C. 1997. "Neues Steuerungsmodell: Local Reform in Germany." In Walter J. M. Kickert (ed.). Public Management and Administrative Reform in Western Europe. Cheltenham and Lyme: Elgar.

Reichart, C. 2001. New Approaches to Public Management. in: K. König, H. Siedentopf, Public Administration in Germany. Baden-Baden 2001,541-556.

Rubinstein, M. and F. Van den Berg. 1992. "Stagnerende veranderingsprocessen." MぬO jaaring 46, 188-204.

Sabel, C. F. 1995. Design, Deliberation, and Democracy: On the New Pragmatism of Firms and Public Institutions, Paper presented to the conference on Liberal Institutions, Economic Constitutional Rights, and the Role of Organizations. European University Institute, Florence.

Schein, E. H. 1985. Organizational Culture and Leadership: A Dynamic View. San Francisco: Jossey-Bass.

Sevón, G. 1996. "Organizational Imitation in Identity Transformation." In B. Czarniawska and G. Sevón (eds). Translating Organizational Change. New York: Walter de Gruyter, 49-68. 
Sobis, I. and M. S. De Vries. 2010. The Story behind Western Advice to Central Europe during its Transition Period. Bratislava: NISPAcee Press.

Sousa, F. H. and J. Vala. 2002. "Relational Justice in Organizations: The Group-Value Model and Support for Change." Social Justice Research 15 (2), 99-121.

Stogdill, R. M. 1948. "Personal Factors Associated with Leadership: A Survey of the Literature." Journal of Personality 25, 35-71.

Stogdill, R. M. and A. E. Coons. 1957. Leader Behavior: Its Description and Measurement. Columbus, $\mathrm{OH}$ : Bureau of Business Research, Ohio State University.

Taylor, F. W. 1998 [1911]. The Principles of Scientific Management. New edn. New York: Dover.

Tengblad, S., F. Hällstén, C. Ackerman and J. Velten. 2010. Medarbetarskap: Från ord till handling. Malmö: Liber AB.

Tengblad, S. 2010. Medarbetarskap på 60 minuter. Högskolan i Skövde. Available at http://stressmedicin.com/upload/Regionkanslierna/ISM\%20Institutet\%20 f\%C3\%B6r\%20stressmedicin/Publikationer/\%C3\%96vrigt/Tengblad\%20 2010,\%20Medarbetarskap\%20p\%C3\%A5\%2060\%20minuter.pdf (last accessed 16 February 2011).

Terry, L. D. 2002. Leadership of Public Bureaucracies: The Administrator as Conservator. New York: M. E. Sharpe.

Tyler, T. R. and D. De Cremer. 2005. "Process-Based Leadership: Fair Procedures and Reactions to Organizational Change." The Leadership Quarterly 16 (4), 529-545.

Wenger, E. 1998. Communities of Practice. Cambridge: Cambridge University Press.

WikiLeaks. 2010. WikiLeaks: Global Defense of Sources and Press Freedoms, circa now. Available at http://mirror.wikileaks.info (last accessed 9 December 2010.

Xu Huang, Kan Shi, Zhijie Zhang and Yat LeeCheung. 2006. "The Impact of Participative Leadership Behavior on Psychological Empowerment and Organizational Commitment in Chinese State-Owned Enterprises: The Moderating Role of Organizational Tenure." Asia Pacific Journal of Management 23 (3). 345-367.

Yukl, G. 2010 [1994]. Leadership in Organization. $7^{\text {th }}$ edn. Englewood Cliffs: Pearson Prentice Hall. 